\title{
Development of a Low Power and Speed Hygienic Vegetable Slicer
}

\author{
${ }^{1}$ I.A. Ola, ${ }^{2}$ A.C. Ogunniyi, ${ }^{3}$ T.M.A, Olayanju and ${ }^{1}$ E.S.A Ajisegiri \\ ${ }^{1}$ Department of Agriculture and Bio-Resources Engineering, COLENG, \\ Federal University of Agriculture, Abeokuta, Nigeria, olaia@funaab.edu.ng, +2348033662968) \\ ${ }^{2}$ Department of General Administration, University College Hospital Ibadan, Oyo State, Nigeria \\ ${ }^{3}$ Landmark University, Omu-Aran, Kwara State Nigeria
}

\begin{abstract}
Most families prefer size reduction of vegetables traditionally, using hand knives on chopping boards in soup making. Advancing from this old method, an affordable low cost slicer was conceived and developed. The unit, a $1.1 \mathrm{~kW}$ motorized vegetable slicer with input and output speed of 920 and $62 \mathrm{rpm}$, respectively was used to slice five different vegetables effectively. Sliced vegetable sizes ranges and estimated operating capacities of 4.6 to $0.7,13.5$ to $1.4,17.1$ to $0.6,14.7$ to 0.5 and 0.6 to $0.2 \mathrm{~cm}$ and $1.8,0.773,0.3545$, 0.2739 and $0.2526 \mathrm{~kg} / \mathrm{min}$ were observed for water leaf, ugwu, cucumber, cabbage and garlic, respectively. High hygienic vegetables slices were obtained with no potent threat of cut to the fingers and hands as do occur in the use of the old method. Such, threats could lead to transference of ailment via. contact from products to the operator and consumer. Vividly this method is better, hygienic, faster and safer the traditional method. Timeliness of processing is enhanced, preventing spoilage as well as improving the quality and the general hygiene of final vegetable product ready for consumption. This machine could easily be deployed in the fast food business to serve the community.
\end{abstract}

Key words: Slicer, cuisines, vegetable, sliced lengths, hygiene, fast food

\section{INTRODUCTION}

Several Africans, particularly Nigerians families enjoy the richness of essential minerals and vitamins derived from consumption of fresh vegetables. The advantage of vegetable consumption to human health and diet were emphasized in reports of Leenders et al. (2013) and Van Duyn and Pivonka (2000). Leenders et al. (2013) investigated the effect of fruit and vegetable consumption on mortality rate a study conducted on cancer and nutrition and concluded that consumption of vegetables reduces the risks of mortality in consumers. Plataforma SINC Plataforma (2014) reiterated that experts have confirmed that fruit and vegetable consumption reduces risk of mortality. Emory (2014) opined that low fruit and vegetable intake is a leading risk factor for death and disability globally and this accounts for approximately 1.7 million annual deaths worldwide. The researcher went further to establish the need for increasing vegetable production globally. FAO., (1981) reported that vegetable productions increase by 3\% between 1975 and 1980 . Sequel to all efforts to increase production of vegetable and consumption globally, there is need to improve on the current method of handling and further processing before it is consumed. Most families in this region prefer size reduction of vegetables before it is used in the final preparations of desired stew or cuisines. However, in these the traditional method which entails the use of hand knives on chopping boards or just hand knives alone were predominantly used.

In Nigeria, fast food industries are becoming trendy and such organizations need a low cost, hygienic vegetable slicer to process the perishable vegetable into high quality indigenous stew that is acceptable to the public and the price of Foreign made vegetable slicer might be too high to acquire by such firms. Numerous works has been done on food processing machines (Akinoso et al., 2008, Olayanju et al., 2013; Aina et al., 2018; Olayanju et al., 2018; Okunola et al., 2018; Osueke et al., 2018; Ezugwu et al., 2019) with little or no focus on vegetable processing machines. This newly developed method of processing vegetables would be grossly quite appealing to fast food industries in Nigeria, since, the unit was design to meet up with demand for productivity and timeliness of operation required in such firms coupled with the interest to increase the present level of vegetable production. Most eateries in Nigeria are still using the

Corresponding Author: E.S.A. Ajisegiri, Department of Agriculture and Bio-Resources Engineering, COLENG, Federal University of Agriculture, Abeokuta, Nigeria, olaia@funaab.edu.ng, +2348033662968) 
traditional method of slicing which is cumbersome and bedeviled with unnecessary exposure to cuts by the sharp cutting kitchen knives on wooden boards. These are all potential sources of contamination which could reduce the overall quality of the end product. It could introduce unwanted blood transfer which may constitute a serious threat to the health of such individual. In fact during the slicing operation, the hygiene measures put in the processing of the food product depends on the state of health of the producer. Any serious health issues by such producers might be transferred through sweats, blood or direct touch of the vegetables into sliced products which constitute health hazards. A contagious disease could be easily transferred causing a great disaster and this potent threat to the health of consumers is eliminated by the development of vegetable slicer.

With the developed slicer, bulk vegetables could be processed on time to much stable form for final consumption under good hygienic condition. Untimely processing of vegetables can lead to great loss due to rapid deterioration at points of harvesting, transportation and temporary storage after harvest (Idah et al., 2007; Okonkwo et al., 2018; Okunola et al., 2019), Aworh and Olorunda (1988), Buyanov and Voronyuk (1885) enumerated that the turbidity of vegetables leaves decreases with decrease in the moisture content due to aging and stomata moisture loses. Sitkei (1986) reported the dynamics of cutting or slicing a given material concluding that the resistance of material to slicing depends on the shape of the cutting edge and given kinematics of cutting. Other scholarly works in slicing vegetables and roots were reported by Ukatu (1994), Brown (1988) and Chancellor (1958).

Timeliness and hygienic slicing of vegetables to attain high quality stew preparation that healthy for consumers is desirable, since, it eliminates human contact and brings improvement on the traditional method of processing vegetables. The development of a small size motorized vegetable slicer for high quality sliced vegetable end products was the essential desirable index that this project focused on.

\section{MATERIALS AND METHODS}

Machine design, description and operation: The machine parts were design and made of stainless steel to avoid food contaminations. The machine's major components are, the barrel which is the housing for the slicing blade. The slicing of vegetable takes place inside the barrel. The barrel also prevents sliced vegetable from falling off or spillage during the cutting process. The tray is situated below the barrel for collecting the sliced vegetable into

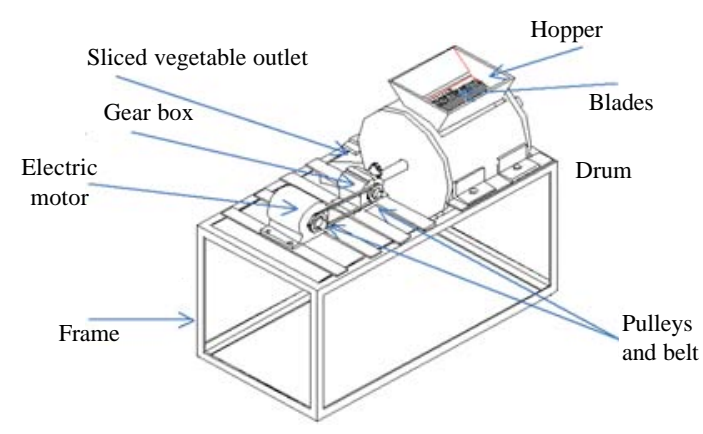

Fig. 1: Isometric view of the vegetable slicer

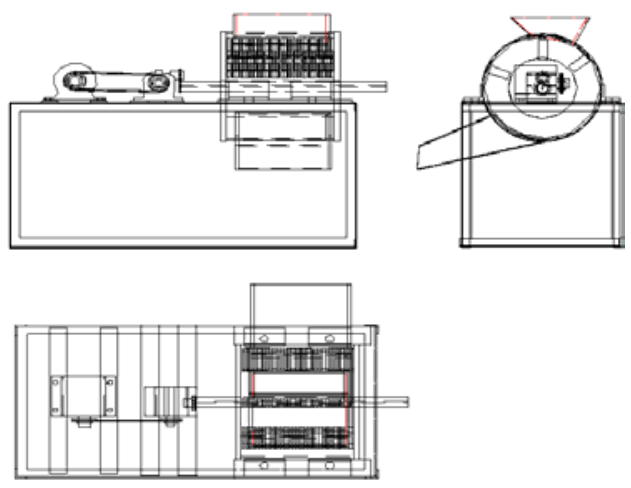

Fig. 2: First angle orthographic projections of the slicing machine

bowls. Other essential parts are as labelled in Fig. 1 while the orthographic projections is shown in Fig. 2. Five vegetables namely, Talinum fruticosum (Water leaf), Telfairia occidentalis (Ugwu), Cucumis sativus (Cucumber), Brassica oleracea var. capitata (Cabbage) and Allium sativum (Garlic) were selected to test the machine. The dimensions of the vegetables were measured using the vernier caliper (IME type) to obtain the average length and diameter of vegetable before and after slicing operation. The weights before and after slicing were also recorded using the sensitive industry electronic balance AMPUT APTP457 series $( \pm 1 \mathrm{~g})$.

Other instruments used during experimentation were a stop watch TAKSUN TS-1809, measuring tape and digital photo tachometer MASTECH DT-2234A. For longer length of vegetables that cannot be measured using the vernier caliper the measuring tape was used. The stop watch was used to monitor the duration of each operation. The speed of the electric motor for slicing the vegetables was measured using the tachometer. The blade thickness for the slicer is $0.6 \mathrm{~mm}$. Evaluation of the effort required to slice a given vegetable precisely "ugwu" was measured using a rig. Ugwu was selected due to the 
assumption that it has high fibre strength than the other five vegetables in appearance. The rig was made of sharp knife attached to a spring balance which measures the slicing force as the knife was used to slice the vegetable. An average force value of $12 \mathrm{~N}$ obtained was used to determine the total effort required by the blade for slicing a bulk volume of vegetables which was in the range of $4.41 \mathrm{Nm}$. This torque was used to design the actual size of electric motor capacity required by the slicer. The relation for determining the power required was obtained using the expression from Budynas and Nisbett.

$$
\mathrm{P}=\mathrm{T} \times \mathrm{t}
$$

Where:

$\mathrm{P}=$ The power required to slice a given bulk volume of vegetable related to the size of the slicing blade

$\mathrm{t}=$ The time obtained from the angular revolution measured by the tachometer

A power rating of $1.1 \mathrm{~kW}$ at $60 \mathrm{rpm}$ was found appropriate for the machine.

\section{RESULTS AND DISCUSSION}

Figure 3 shows the machine developed and Fig. 4 are the processed vegetables obtained while testing the machine to determine the slicing efficiency on the five vegetables. The initial and final dimensional measurements of vegetables being processed are given in Table 1. The range in length size reduction of sliced vegetables observed varied from $0.2-1.4 \mathrm{~cm}$.

The machine performed excellently well by reducing the vegetables to the desired acceptable length for making indigenous stew. The machine effectively reduced the vegetables to short lengths within short time of operation with operating capacity ranging from $4.21-30 \times 10^{-3} \mathrm{~kg} / \mathrm{sec}$. These rates were far greater than the traditional kitchen knife slicing method which in addition is cumbersome and prone to hand injury that could lead to food contaminations (Fig. 5).

In processing garlic, it was observed that more effort was required to slice the vegetable as indicated in the operating capacity obtained. This also showed the resistance of the vegetable to slicing blade due to the tough fibre content of the vegetable, hence, the highest operating capacity $\left(30 \times 10^{-3} \mathrm{~kg} / \mathrm{sec}\right)$ was observed for garlic as compared to what was obtained in other four vegetables. The least operating capacity of $4.21 \times 10^{-3} \mathrm{~kg} / \mathrm{sec}$ occurs with cabbage which signifies that the vegetable is softer the than other four vegetables. The

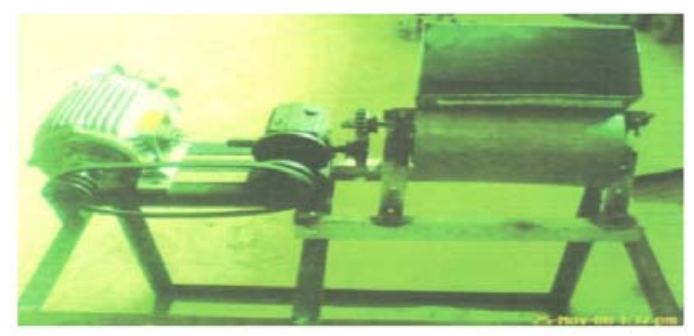

Fig. 3: Prototype vegetable slicer

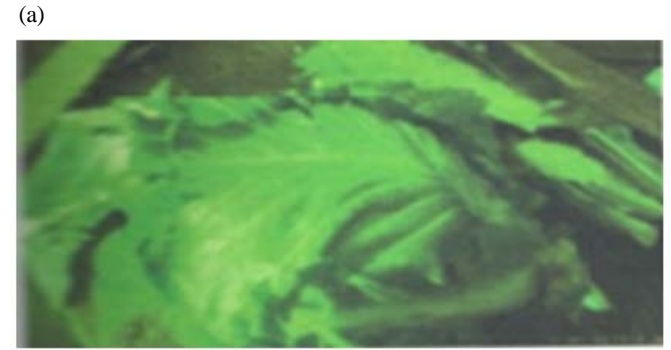

(b)

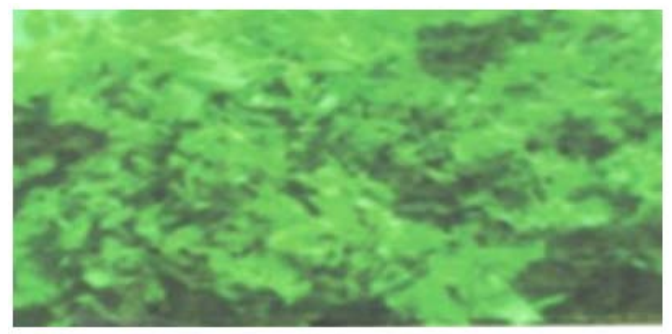

Fig. 4: a) Cabbage before slicing and b) Cabbage after slicing

(a)

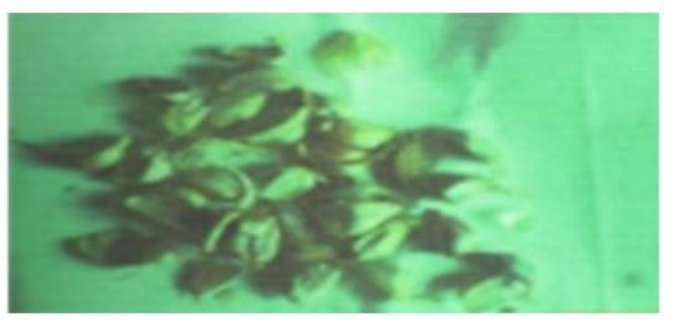

(b)

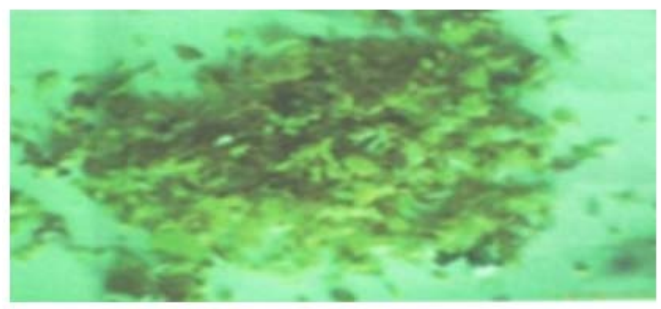

Fig. 5: a) Garlic before slicing and b) Garlic after slicing 
Table 1: Results of the sliced vegetables

\begin{tabular}{lcccccccc}
$\begin{array}{l}\text { Vegetable } \\
\text { sample }\end{array}$ & $\begin{array}{c}\text { Initial } \\
\text { weight }(\mathrm{kg})\end{array}$ & $\begin{array}{c}\text { Initial maximum } \\
\text { length }(\mathrm{cm})\end{array}$ & $\begin{array}{c}\text { Initial minimum } \\
\text { length }(\mathrm{cm})\end{array}$ & $\begin{array}{c}\text { Final sliced } \\
\text { length }(\mathrm{cm})\end{array}$ & $\begin{array}{c}\text { Time } \\
\text { length }\end{array}$ & $\begin{array}{c}\text { Size reduction } \\
\text { efficiency }(\%)\end{array}$ & $\begin{array}{c}\text { Reduction } \\
\text { factor }\end{array}$ & $\begin{array}{c}\text { Operating capacity } \\
\text { (kg/sec) }\end{array}$ \\
\hline Water leaf & 1.8 & 4.6 & 1.4 & 0.7 & 140 & 92.4 & 13 & 0.01286 \\
Ugwu & 1.3 & 13.5 & 8.2 & 1.4 & 220 & 98.2 & 56 & 0.00591 \\
Cucumber & 2.1 & 17.1 & 7.2 & 0.6 & 460 & 99.7 & 342 & 0.00457 \\
Cabbage & 2.4 & 14.7 & 9.4 & 0.5 & 570 & 99.8 & 552 & 0.00421 \\
Garlic & 1.2 & 0.6 & 0.4 & 0.2 & 40 & 83.3 & 5 & 0.03000 \\
\hline
\end{tabular}

(a)

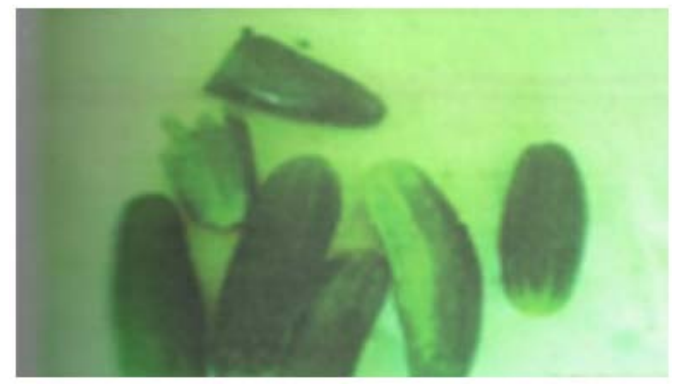

(b)

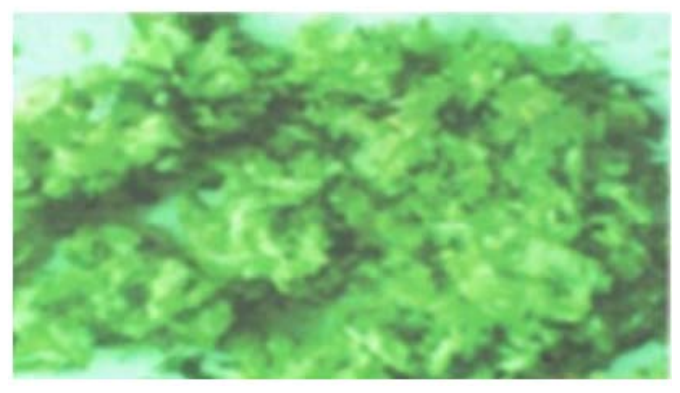

Fig. 6: a) Cucumber before slicing and b) Cucumber after slicing

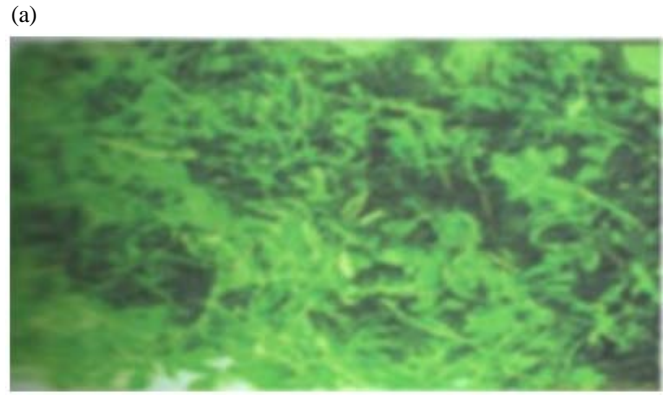

(b)

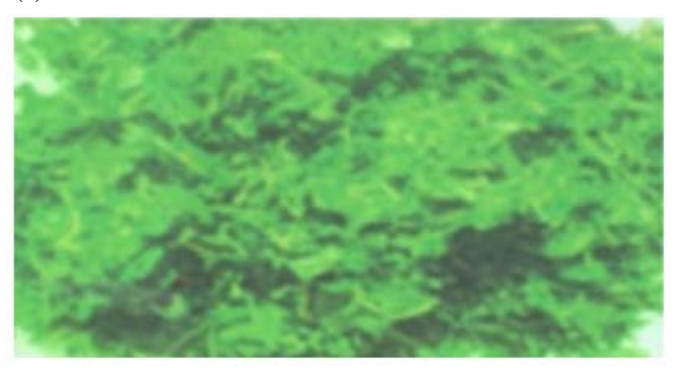

Fig. 7: a) Ugwu before slicing and b) Ugwu after slicing

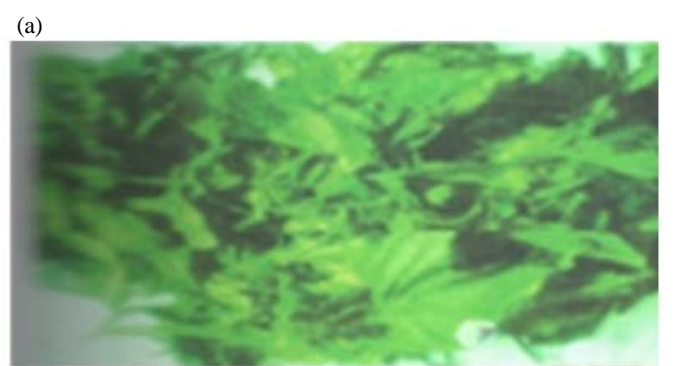

(b)

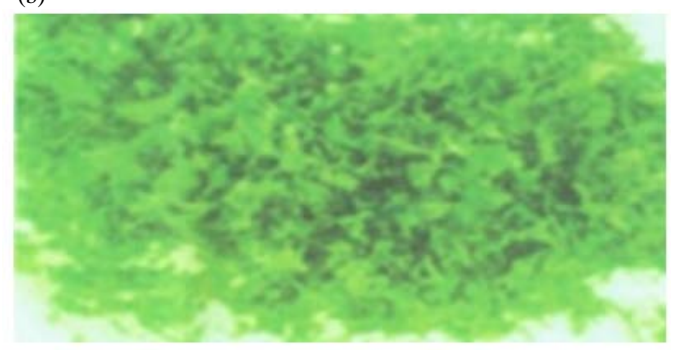

Fig. 8a): Water leaf before slicing and b) Water leaf after slicing

various operating capacities for each vegetables depicts the effort required to process each one to the lengths obtained as shown in Table 1 and Fig. 4 (Fig. 6-8).

\section{CONCLUSION}

A low scale vegetable slicer developed appropriately reduced the five selected vegetables to the desired sizes to meet up with the hygienic quality required for mass production of public food in fast food industries in Nigeria. There is need for all stakeholders, both domestic and industrial food producers to embrace and explore the immense benefit of the use of this machine at all levels of production.

\section{RECOMMENDATIONS}

Future upgrading of the machine from stainless parts to plastic parts for low cost and advance development could be made into industrial scale for large commercial productions with compact parts to meet the needs of the populace of vegetable demands in Nigeria. 


\section{ACKNOWLEDGEMENT}

The Federal University of Agriculture, Abeokuta provided the ambient for developing the machine while Landmark University, Omu-Aran provided the fund.

\section{REFERENCES}

Aina, E.O., A.F. Adisa and T.M.A. Olayanju, 2018. Performance evaluation of a developed cashew nut shell liquid expeller. Agric. Eng., 22: 5-19.

Akinoso, R., T.M.A. Olayanju and L.K. Bankole, 2008. Design, fabrication and testing of a roaster for palm (Elaeis guineensis) kernel. J. Food Sci. Technol., 45: 92-93.

Akinoso, R., T.M.A. Olayanju, L.O. Hassan and Ajiboshin, 2010. Design, construction and preliminary testing of a beniseed (Sesamum indicum) air-screen cleaner. ASSET-Int. J. Ser. B, 9: 155-162.

Aworh, O.C. and A.O. Olorunda, 1988. Packaging and storing technology of fresh fruits and vegetables with special references to tropical conditions. Proceedings of the National Workshop on Improved Packaging and Storage System for Fruits and Vegetables, Ilorin, Nigeria, March 30, 1988, Nigerian Stored Products Research Institute, Nigeria, pp: 75-91.

Brown, R.H., 1988. Handbook of Engineering in Agriculture. Vol. 1, CRC Press, Boca Raton, Florida, USA., ISBN:9780849338618, Pages: 288.

Budynas, R. and K. Nisbett, 2006. Shigley's Mechanical Engineering Design. 8th Edn., McGraw-Hill, New York, ISBN: 9780073312606.

Buyanov, A.I. and B.A. Voronyuk, 1985. Physical and Mechanical Properties of Plants, Fertilizers and Soils. Amerind Publishing Co. Pvt. Ltd., New Delhi, India, ISBN:9788120500143, Pages: 528.

Chancellor, W.J., 1958. Energy requirement for cutting forage. Agric. Eng., 39: 633-640.

Emory, 2014. Study shows global need to produce more fruits and vegetables. Woodruff Health Sciences Center Library, Druid Hills, Georgia, USA. https://news.emory.edu/stories/2014/08/study_sho ws_more_fruits_vegetables_needed/index.html.

Ezugwu, C.A., C.O. Osueke, A.O. Onokwai, R.S. Diarah and T.M.A. Olayanju et al., 2019. Design and fabrication of a motorized/power operated plantain slicer for optimum chips production. Intl. J. Mech. Eng. Technol., 10: 1485-1495.
FAO., 1981. Food loss prevention in perishable crops. FAO. Agricultural Services Bulletin No. 43, FAO, Rome, Italy.

Idah, P.A., E.S.A. Ajisegiri and M.C. Yisa, 2007. Fruits and vegetables handling and transportation in Nigeria. Aust. J. Technol., 10: 175-183.

Leenders, M., I. Sluijs, M.M. Ros, H.C. Boshuizen and P.D. Siersema et al., 2013. Fruit and vegetable consumption and mortality: European prospective investigation into cancer and nutrition. Am. J. Epidemiol., 178: 590-602.

Okonkwo, C.E., A. Olaniran, J.O. Ojediran, T.A. Olayanju and F. Ajao et al., 2018. Design, development and evaluation of locust bean seed dehuller. J. Food Process Eng., 42: 1-8.

Okunola, A.A., A. Isaac-Bamgboye, A. Olayanju, C.O. Osueke and E.A. Alhassan, 2018. Development of a rice cleaner cum grader for cottage industry processors in Nigeria. Intl. J. Mech. Eng. Technol., 9: 2339-2351.

Okunola, A.A., T.A. Adekanye, A. Ayooluwa, C.E. Okonkwo and S.A. Alake et al., 2019. Development of a locust bean seed dehulling cum washing machine. Intl. J. Mech. Eng. Technol., 10: 1321-1330.

Olayanju, T.A., C.E. Okonkwo, J.O. Ojediran, A.S. Alake and A.A. Okunola et al., 2018. Development of an improved gari fryer. Int. J. Mech. Eng. Technol., 9: 769-788.

Olayanju, T.M.A., L.O. Hassan, W.B. Asiru and R. Akinoso et al., 2013. Design and development of a semi-continuous beniseed oil and edible cake processing plant. Proceedings of the International Conference on a Preliminary Design Report on Phase Two of the RMRDC/FIIRO Collaborative Project, October 12-14, 2003, Federal Institute of Industrial Research Oshodi, Lagos, Nigeria, pp: 1-78.

Osueke, C.O., T.M.A. Olayanju, A.O. Onokwai and P. Uzendu, 2018. Design and construction of an automatic fish feeder machine. Int. J. Mech. Eng. Technol., 9: 1631-1645.

Plataforma, S., 2014. Experts confirm that fruit and vegetable consumption reduces risk of mortality. ScienceDaily LLC, Rockville, Maryland, USA. https://www.sciencedaily.com/releases/2013/09/130 926102433.htm

Sitkei, G., 1986. Mechanics of Agricultural Materials. Elsevier, Amsterdam, Netherlands, ISBN: 9780444995230, Pages: 487.

Ukatu, A.C., 1994. Design, construction and performance evaluation of an industrial yam peeling and slicing machine. Ph.D Thesis, Department of Agricultural Engineering, University of Ibadan, Nigeria.

Van Duyn, M.A. and E. Pivonka, 2000. Overview of the health benefits of fruit and vegetable consumption for the dietetics professional: Selected literature. J. Am. Dietetic Assoc., 100: 1511-1521. 